\title{
Synthesis of stable cesium superoxide nanoparticles for gas sensing application by solution-processed spray pyrolysis method
}

\author{
K. R. Nemade ${ }^{1} \cdot$ S. A. Waghuley ${ }^{2}$
}

Received: 10 July 2016/Accepted: 11 October 2017/Published online: 16 October 2017

(c) The Author(s) 2017. This article is an open access publication

\begin{abstract}
In the present work, we synthesized cesium superoxide $\left(\mathrm{CsO}_{2}\right)$ nanoparticles by solution-processed spray pyrolysis technique. The as-synthesized $\mathrm{CsO}_{2}$ nanoparticles were characterized through Raman spectroscopy, X-ray diffraction, scanning electron microscopy and ultraviolet-visible spectroscopy. The $\mathrm{CsO}_{2}$ nanoparticle-based gas sensor is more selective towards the carbon dioxide $\left(\mathrm{CO}_{2}\right)$ gas. The sensor shows good gas sensing performance for $\mathrm{CO}_{2}$ gas. Gas sensing mechanism is dominated by the adsorption and desorption process. Through this paper, we studied another dimension of gas sensing process by employing superoxide for gas sensing. The sensing mechanism for cesium superoxide is explained by newly designed "bridging oxygen-free mechanism".
\end{abstract}

Keywords Spray pyrolysis - Cesium superoxide $\cdot$ Gas sensing

\section{Introduction}

The superoxides have been a subject of growing interest because of its extraordinary characteristics resulting from superoxide ion $\left(\mathrm{O}_{2}^{-}\right)$(Budanur and Khan 2014). The study of superoxide ion can facilitate understanding its role in metal-oxygen batteries. Ren et al. reported the metaloxygen battery application of potassium superoxide

K. R. Nemade

krnemade@gmail.com

1 Department of Physics, Indira Mahavidyalaya, Kalamb 445401, India

2 Department of Physics, Sant Gadge Baba Amravati University, Amravati 444 602, India nanoparticles. This study successfully confirms formation and removal of $\mathrm{KO}_{2}$ in the battery cycle test. Moreover, without any catalysts, a low discharge/charge potential gap of the order of $50 \mathrm{mV}$ was observed (Ren and $\mathrm{Wu} 2013$ ). Bryantsev et al. (2011) reported the predicting solvent stability of aprotic electrolyte Li-air batteries by the superoxide anion radical. This experimental study provides competent qualitatively screening solvent stability in Li-air batteries. Hartmann et al. (2013) reported the rechargeable room-temperature battery application of sodium superoxide. This study shows that exchange of lithium by sodium may offer an unforeseen route towards rechargeable metalair batteries.

Inspiring from the extraordinary characteristics resulting from superoxide ion $\left(\mathrm{O}_{2}{ }^{-}\right)$in superoxide, we planned to study the gas sensing application of cesium superoxide nanoparticles. A very small number and scattered reports found in the literature of material science on superoxide. Thus, through this work, we make an attempt to explore gas-sensing performance of cesium superoxide nanoparticles. As the superoxide itself contains the superoxide ion $\left(\mathrm{O}_{2}{ }^{-}\right)$, therefore, we developed "bridging oxygen-free mechanism" for superoxide.

The core objective behind the development of "bridging oxygen-free mechanism" for gas sensing materials are that it will result in fast sensing, selectivity and fast response and recovery time. This is due to the traditional gas sensing material-bridging oxygen forms layer between target gas molecules and sensing surface, but the superoxide-based sensing materials itself contain superoxide ion $\left(\mathrm{O}_{2}{ }^{-}\right)$. Generally, in resistive gas-sensing method, bridging oxygen forms layer on sensing material, through which electron transfer takes place (Alwan and Dheyab 2017). The transfers of electrons result in resistance change through which sensing response is measured (Muhsien et al. 2014). 
The formation of bridging oxygen layer acts as a barrier between target gas and sensing surface for rapid detection of target gas. In addition, formation of bridging oxygen layer on sensing surface increases response and recovery time of sensor. Therefore, UV light exposure is given to sensor surface to achieve baseline value of resistance (Chinh et al. 2016). This increases the operation cost and decreases the life of sensor.

\section{Experimental}

In the present work, cesium superoxide $\left(\mathrm{CsO}_{2}\right)$ was prepared by solution-processed spray pyrolysis technique. For the synthesis of $\mathrm{CsO}_{2}$ nanoparticles, cesium chloride $(\mathrm{CsCl})$ and hydrogen peroxide $\left(\mathrm{H}_{2} \mathrm{O}_{2}\right)$ was used as starting chemicals. The $1 \mathrm{M}$ of cesium chloride was dissolved in $\mathrm{H}_{2} \mathrm{O}_{2}$ under rapid magnetic stirring in distilled water of resistivity not less than $18.2 \mathrm{M} \Omega \mathrm{cm}$ for $15 \mathrm{~min}$. Subsequent to this step; solution was kept for probe sonication. After this step, solution was loaded in spray pyrolysis setup of specification (Nemade and Waghuley 2014a). This solution was allowed to spray and deposit on chemically clean glass substrate maintained at temperature $100^{\circ} \mathrm{C}$. The complete process was conducted in dry oxygen-rich environment under constant flow. By considering the highly reactive nature of cesium, the complete process was handled in an atmosphere of water below $0.1 \mathrm{ppm}$.

The highly conducting silver paste was used as ohmic contacts to determine the film surface resistance change measurements. The as-deposited $\mathrm{CsO}_{2}$ nanoparticles on chemically cleaned $\mathrm{SiO}_{2}$ substrate of dimensions $25 \mathrm{~mm} \times 25 \mathrm{~mm}$ used for gas sensing action. The gas sensing performance of chemiresistor was checked in air as reference gas. The sensing response $(S)$ is defined as $S=\left|R_{\mathrm{a}}-R_{\mathrm{g}}\right| / R_{\mathrm{a}}$, where $R_{\mathrm{a}}$ is the resistance in air i.e., baseline resistance and $R_{\mathrm{g}}$ represents the resistance in $\mathrm{CO}_{2}$ gas.

\section{Results and discussion}

Figure 1 shows the Raman spectrum of as-synthesized $\mathrm{CsO}_{2}$ nanoparticles at room temperature $(303 \mathrm{~K})$. The spectra exhibit the sharp intense peak at $1134 \mathrm{~cm}^{-1}$, which can be assigned to the stretching mode of the superoxide dumbbell. This reflects as-synthesized $\mathrm{CsO}_{2}$ nanoparticles acquire hyperoxide state. The inset of Fig. 1 shows XRD pattern of $\mathrm{CsO}_{2}$ nanoparticles, indicates the presence of a very low concentration of peroxide anions, which might result from incomplete oxidation (Bates et al. 1972). The $\mathrm{CsO}_{2}$ acquires the space group $\mathrm{I} / 4 \mathrm{mmm}$ with lattice

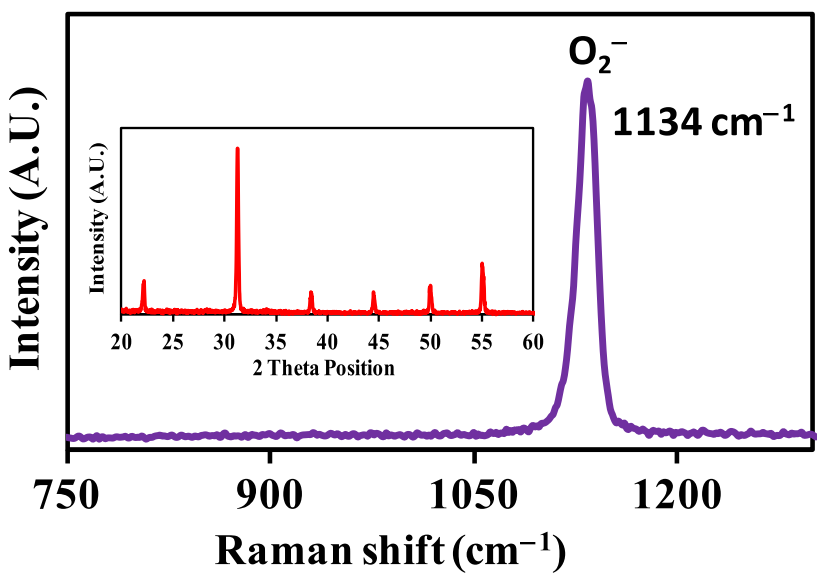

Fig. 1 Raman spectrum of as-synthesized $\mathrm{CsO}_{2}$ nanoparticles at room temperature. The sharp peak at $1134 \mathrm{~cm}^{-1}$ is attributed to the superoxide anion that is $\mathrm{O}-\mathrm{O}$ stretching mode. Inset shows XRD pattern of intermediate phase $\mathrm{CsO}_{2}$ nanoparticles obtained from incomplete oxidation

parameters at temperature $303 \mathrm{~K}, a=b=4.461 \AA$ A and $c=7.331 \AA$ A. Generally, superoxides have the largest lattice parameters, which is consequential to larger distance between the dioxygen dumbbells and cesium. Therefore, lower cationic field experienced by the dumbbells. Thus, even in oxygen-rich reaction environment, superoxides do not merge entirely superionic state (Zumsteg et al. 1974). The average crystallite size of as-synthesized $\mathrm{CsO}_{2}$ nanoparticles was estimated using Debye-Scherrer formula (Nemade and Waghuley 2013a, 2014b), $D=0.89 \lambda / \beta \cos \theta$, where 0.89 is Scherrer's constant, $\lambda$ is the wavelength of $\mathrm{X}$-rays, $\theta$ is the Bragg diffraction angle, and $\beta$ is the full width at half maximum. The average particle size of the $\mathrm{CsO}_{2}$ nanoparticles was found to be $21.39 \mathrm{~nm}$.

Figure 2 represents the SEM image of as-synthesized $\mathrm{CsO}_{2}$ nanoparticles. This image substantiates the irregular shape of the nanoparticles, and most of the particles exhibit small amount of agglomeration. From the image, it is observed that the size of the nanoparticle is around $22 \mathrm{~nm}$, which was in good agreement with the particle sizes $(21.39 \mathrm{~nm})$ calculated from the Debye-Scherrer formula.

The UV-VIS absorption spectroscopy is used to analyze the optical properties of $\mathrm{CsO}_{2}$ nanoparticles. The as-synthesized $\mathrm{CsO}_{2}$ nanoparticles exhibit excitonic absorption tail around $225 \mathrm{~nm}$. The monodisperse nature of the $\mathrm{CsO}_{2}$ nanoparticle distribution reflects from sharp increase in absorbance value (Zhang et al. 2002). The optical band gap of as-synthesized $\mathrm{CsO}_{2}$ nanoparticles was determined by applying the energy-wavelength relation (Nemade and Waghuley 2013b). The optical band gap is determined by extrapolating straight line at $R=0$ to the curve $(\alpha \mathrm{hv})^{2}$ vs. $(h v)$ is shown in inset of Fig. 3. This extrapolation intersect energy axis at $5.3 \mathrm{eV}$. This is optical band gap of $\mathrm{CsO}_{2}$ 
Fig. 2 FE-SEM image of assynthesized $\mathrm{CsO}_{2}$ nanoparticles

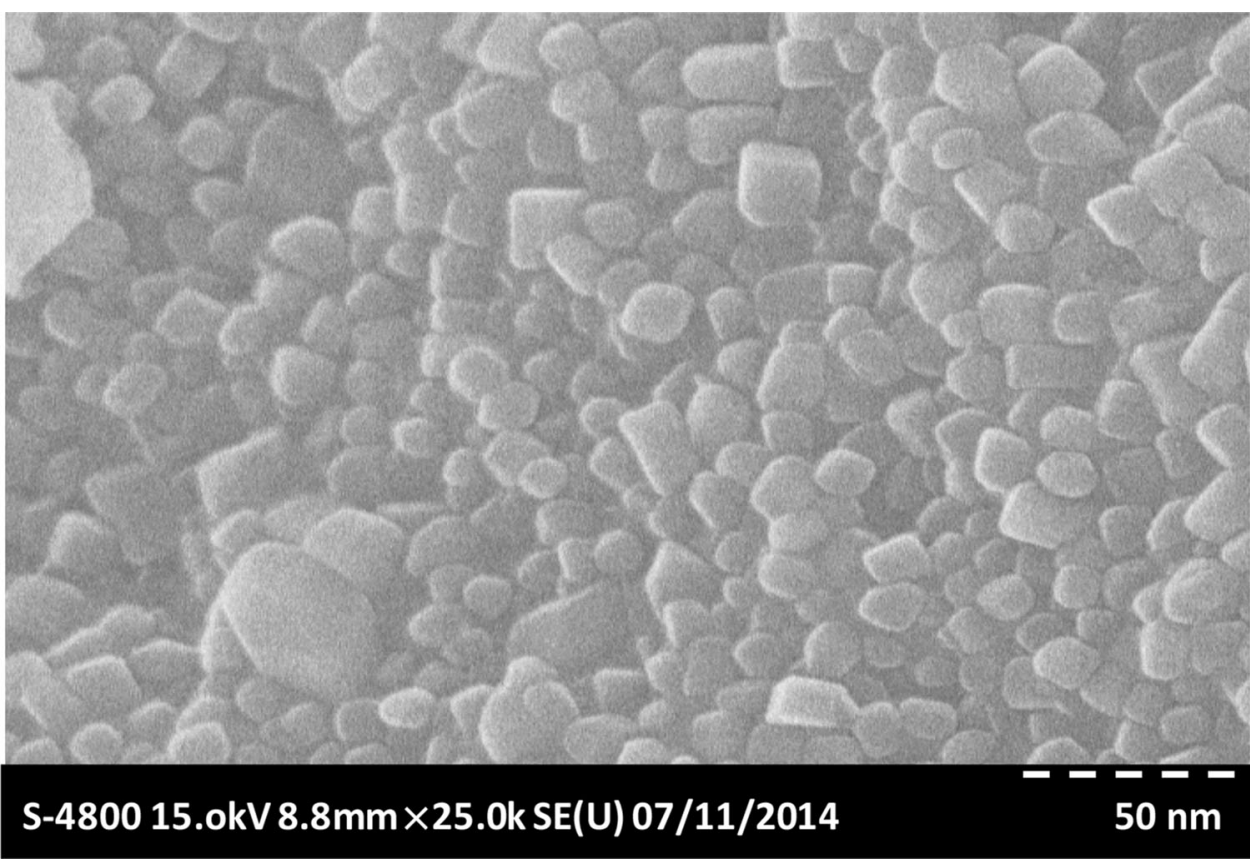

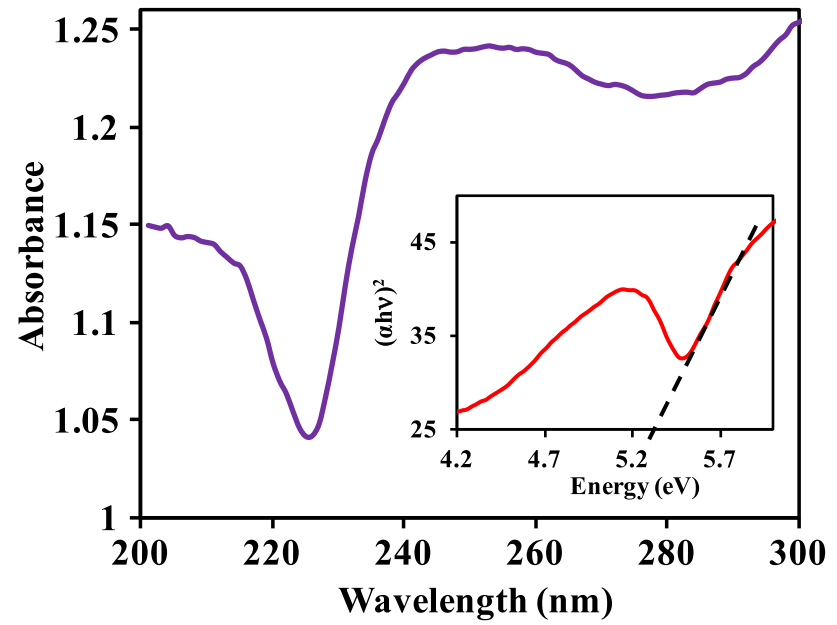

Fig. 3 UV-VIS spectrum of $\mathrm{CsO}_{2}$ nanoparticles and inset shows the optical band gap plot showing $\mathrm{CsO}_{2}$ nanoparticles have band gap $5.3 \mathrm{eV}$

nanoparticles. The intense absorption around the $225 \mathrm{~nm}$ indicates the presence of quantum confinement (Nemade and Waghuley 2013c).

The selectivity is the ability of a sensor to measure only one gas with maximum response (Morrison 1987). To check selectivity response of $\mathrm{CsO}_{2}$ nanoparticles-based sensor, we investigate sensing response towards the LPG and $\mathrm{CO}_{2}$ gas at $250 \mathrm{ppm}$ at room temperature as shown in Fig. 4. Plot clearly shows that $\mathrm{CsO}_{2}$ nanoparticles exhibits higher sensing response towards the $\mathrm{CO}_{2}$ gas. Therefore, as-synthesized $\mathrm{CsO}_{2}$ nanoparticles are more selective for $\mathrm{CO}_{2}$ gas. Thus, the future study focused on $\mathrm{CO}_{2}$ gas sensing.

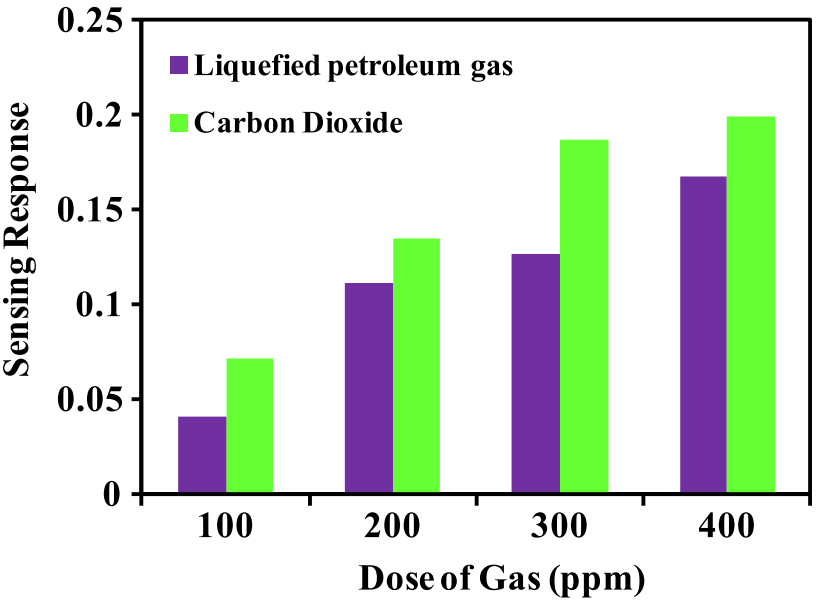

Fig. 4 Selectivity performance of $\mathrm{CsO}_{2}$ nanoparticles against LPG and $\mathrm{CO}_{2}$ gas

Figure 5 depicts the gas sensing response of $\mathrm{CsO}_{2}$ nanoparticles towards the $\mathrm{CO}_{2}$ gas at room temperature (303 K). The plot clearly shows the good dependence on the $\mathrm{CO}_{2}$ concentration. Sensing response curve has nearly linear fitting $\left(R^{2}=0.9933\right)$ with $\mathrm{CO}_{2}$ gas concentration. The resistance of $\mathrm{CsO}_{2}$ nanoparticles increases in the presence of $\mathrm{CO}_{2}$ gas. This reflects the n-type behavior of as-synthesized $\mathrm{CsO}_{2}$ nanoparticles (Nemade and Waghuley 2013d, 2015b). The increase in resistance is also indicating the oxidizing nature of $\mathrm{CO}_{2}$ gas. The oxidizing gases have tendency to inject electron for sensing surface. This results in reduction of electron density in conduction band of sensing surface (Nemade and Waghuley 2015a). Therefore, resistance of $\mathrm{CsO}_{2}$ sensing surface is increase in the presence of $\mathrm{CO}_{2}$ gas. 


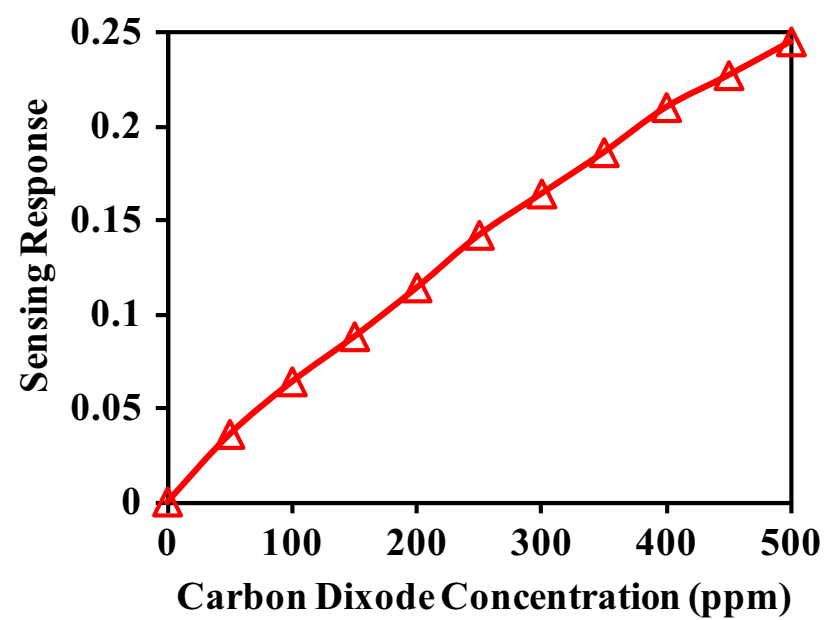

Fig. 5 Sensing response of $\mathrm{CsO}_{2}$ nanoparticles towards the $\mathrm{CO}_{2}$ gas at room temperature $(303 \mathrm{~K})$

Generally, gas sensing mechanism is dominated by the adsorption and desorption process through oxygen species (Fig. 6a). This is known as oxygen bridging mechanism. But in case of the materials, which itself contains superionic species such as $\mathrm{O}_{2}{ }^{-}$, that is superoxide oxide, oxygen bridging mechanism laps. This may be due to adsorption of oxygen is not necessary for superoxide oxide. Therefore, it is necessary to develop mechanism for gas sensing by superoxide oxide. Through this paper, we proposed this mechanism, which is termed as "bridging oxygen-free mechanism" (Fig. 6b). According to this mechanism during the gas sensing, $\mathrm{CO}_{2}$ directly converted into the surface carbonates, without adsorption of oxygen molecules, which is generally observed in another materials.

Figure 7 shows that the operating temperature response of $\mathrm{CsO}_{2}$ nanoparticle-based sensor was studied towards the $250 \mathrm{ppm} \mathrm{CO} \mathrm{CO}_{2}$ gas. The sensing response value increases up to $448 \mathrm{~K}$. Beyond $448 \mathrm{~K}$, sensing response starts to decrease. This is the operating temperature $(448 \mathrm{~K})$ for asfabricated sensor. This decrease in sensing response may

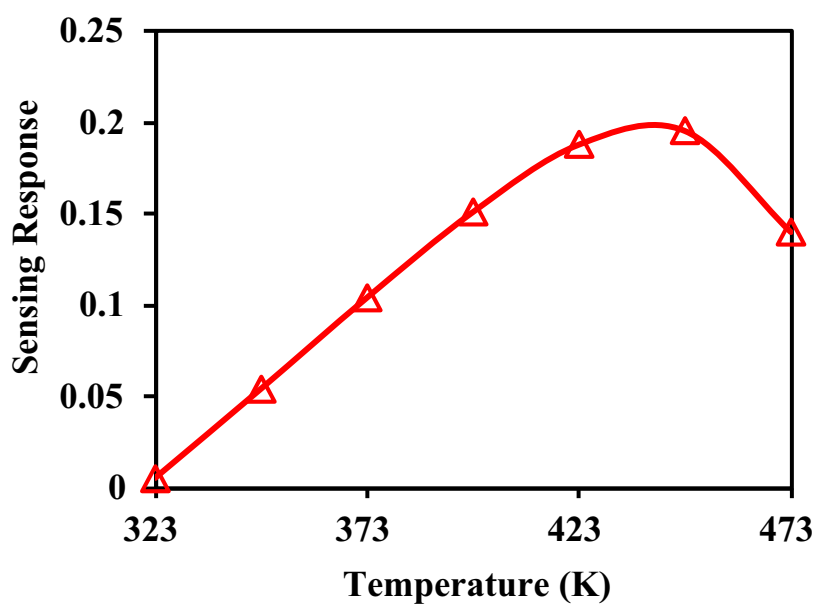

Fig. 7 Operating temperature performance of $\mathrm{CsO}_{2}$ nanoparticles towards $250 \mathrm{ppm} \mathrm{CO}_{2}$

attribute to desorption of gas molecules. Beyond fixed temperature, the response value starts to decrease, which is assigned to desorption of adsorbed oxygen molecules from sensing surface. At higher temperature, due to increase in internal thermal vibration adsorbed oxygen is detached from the sensing surface (Nemade and Waghuley 2013e).

Figure 8 shows transient response of $\mathrm{CsO}_{2}$ nanoparticles towards $250 \mathrm{ppm} \mathrm{CO}_{2}$ gas at room temperature. The plot shows sensor-exhibited fast response time around $50 \mathrm{~s}$ and recovery time $40 \mathrm{~s}$. This shows that sensors have good practical applicability. The fast response and recovery time attributed to fast interaction between target gas molecules and superoxide-based sensing material. The fast interaction between gas and sensing surface is due to absence of bridging oxygen layer as $\mathrm{CsO}_{2}$ nanoparticles itself contains superionic species such as $\mathrm{O}_{2}^{-}$.

Figure 9 shows the stability performance of $\mathrm{CsO}_{2}$ nanoparticles against $250 \mathrm{ppm} \mathrm{CO}_{2}$ gas at room temperature. The sensing curve shows nearly stable response for the entire month.
Fig. 6 Comparison of gas sensing mechanism between metal oxide and superoxide based resistive gas sensor (a)

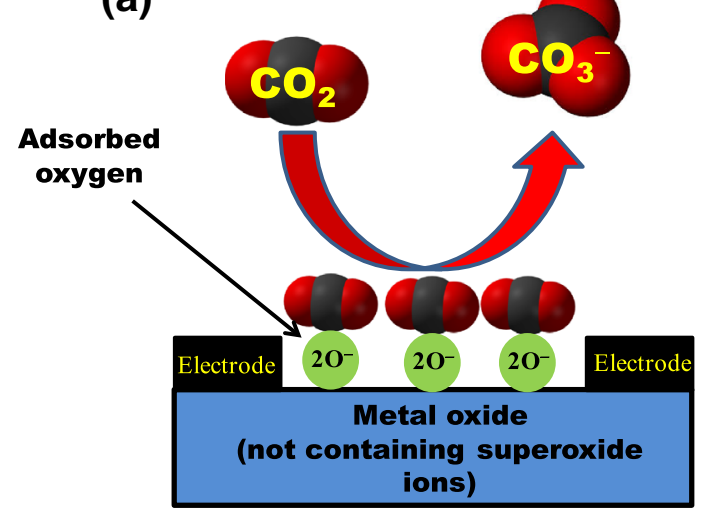

(b)

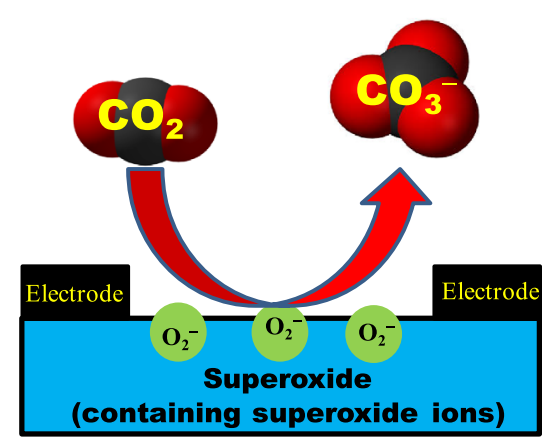




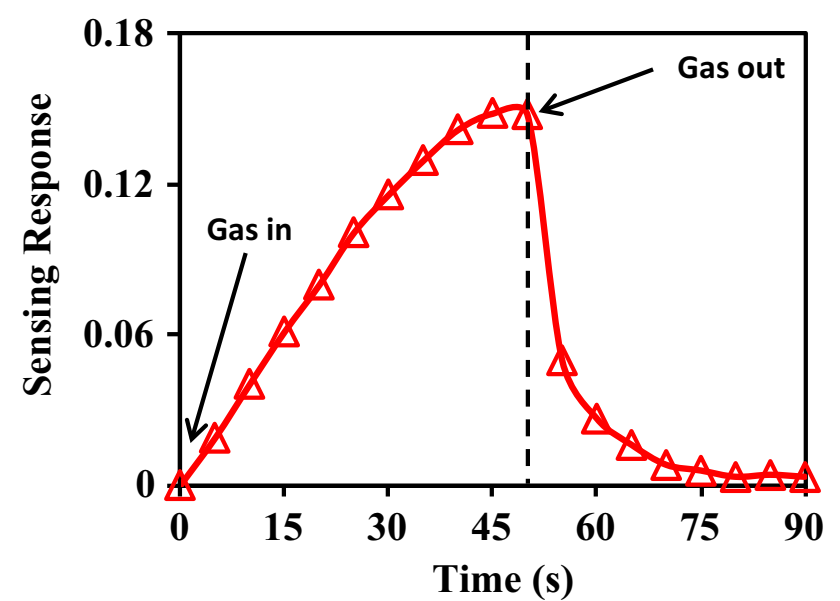

Fig. 8 Transient response of $\mathrm{CsO}_{2}$ nanoparticles towards $250 \mathrm{ppm}$ $\mathrm{CO}_{2}$ at room temperature $303 \mathrm{~K}$

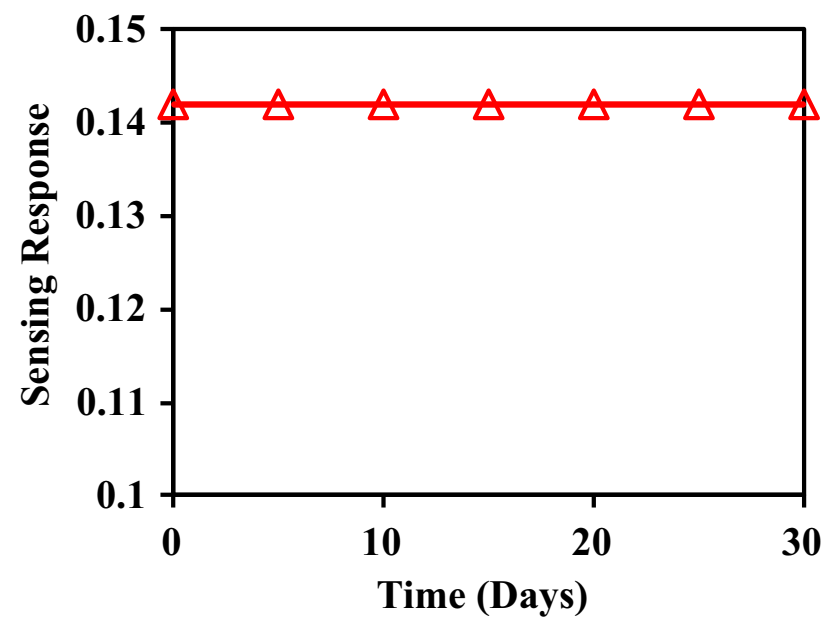

Fig. 9 Stability response of $\mathrm{CsO}_{2}$ nanoparticles towards $250 \mathrm{ppm}$ $\mathrm{CO}_{2}$ at room temperature $303 \mathrm{~K}$

\section{Conclusions}

Stable $\mathrm{CsO}_{2}$ nanoparticles were prepared by solution-processed spray pyrolysis method. The prepared particles were characterized by various techniques to confirm structural, chemical and optical purity. The Raman spectroscopy directly shows that as-synthesized nanoparticles contain the superoxide ions. The gas sensing performance of $\mathrm{CsO}_{2}$ nanoparticles towards the $\mathrm{CO}_{2}$ gas quite fit for practical application. The operating temperature was found to be $448 \mathrm{~K}$. The as-fabricated sensor shows good stability and rapid response and recovery time. The fast response and recovery time characteristic of sensor is attributed to "bridging oxygen-free mechanism". The study towards further development of "bridging oxygen-free mechanism" is currently underway in our lab.
Acknowledgements The authors acknowledge Prof. S.K. Omanwar, Head, Department of Physics, Sant Gadge Baba Amravati University, Amravati for providing necessary facilities for the work.

Open Access This article is distributed under the terms of the Creative Commons Attribution 4.0 International License (http:// creativecommons.org/licenses/by/4.0/), which permits unrestricted use, distribution, and reproduction in any medium, provided you give appropriate credit to the original author(s) and the source, provide a link to the Creative Commons license, and indicate if changes were made.

\section{References}

Alwan AM, Dheyab AB (2017) Room temperature CO2 gas sensors of AuNPs/mesoPSi hybrid structures. Appl Nanosci 7:335

Bates JB, Boyd GE, Brooker MH (1972) Raman spectra of O- 2 and O- 3 ions in alkali-metal superoxides and ozonides. Chem Phys Lett $16: 391$

Bryantsev VS, Giordani V, Walker W, Blanco M, Zecevic S, Sasaki K, Uddin J, Addison D, Chase GV (2011) Predicting solvent stability in aprotic electrolyte $\mathrm{Li}$-air batteries: nucleophilic substitution by the superoxide anion radical (O2•-). J Phys Chem A 115:12399

Budanur BM, Khan FA (2014) Superoxide chemistry revisited: synthesis of tetrachloro-substituted methylenenortricyclenes. Beilstein J Org Chem 10:2531

Chinh ND, Quang ND, Lee H, Hien TT, Hieu NM, Kim D, Kim C, Kim D (2016) NO gas sensing kinetics at room temperature under UV light irradiation of In2O3 nanostructures. Sci Rep 6:35066

Hartmann P, Bender CL, Vracar M, Durr AK, Garsuch A, Janek J, Adelhelm P (2013) A rechargeable room-temperature sodium superoxide $(\mathrm{NaO} 2)$ battery. Nat Mater 12:228

Morrison SR (1987) Selectivity in semiconductor gas sensors. Sens Actuators 12:425

Muhsien MA, Salem ET, Agool IR, Hamdan HH (2014) Gas sensing of $\mathrm{Au} / \mathrm{n}-\mathrm{SnO} 2 / \mathrm{p}-\mathrm{PSi} / \mathrm{c}-\mathrm{Si}$ heterojunction devices prepared by rapid thermal oxidation. Appl Nanosci 4:719

Nemade KR, Waghuley SA (2013a) Synthesis and characterization of bismuth oxide quantum dots. Adv Sci Eng Med 5:988

Nemade KR, Waghuley SA (2013b) Low temperature synthesis of semiconducting $\alpha$-Al 2 O 3 quantum dots. Ceramics Int 40:6109

Nemade KR, Waghuley SA (2013c) LPG sensing application of graphene/CeO 2 quantum dots composite. AIP Conf Proc 1536:1258

Nemade KR, Waghuley SA (2013d) Carbon dioxide gas sensing application of graphene/Y2O3 quantum dots composite. Int J Modern Phys Conf Series 22:380

Nemade KR, Waghuley SA (2013e) Chemiresistive gas sensing by few-layered graphene. J Electron Mater 42:2857

Nemade KR, Waghuley SA (2014a) Synthesis of MgO nanoparticles by solvent mixed spray pyrolysis technique for optical investigation. Int J Metals 2014:389416

Nemade KR, Waghuley SA (2014b) Role of defects concentration on optical and carbon dioxide gas sensing properties of $\mathrm{Sb} 2 \mathrm{O}$ 3/graphene composites. Opt Mater 36:712

Nemade KR, Waghuley SA (2015a) Comparative study of carbon dioxide sensing by Sn-doped $\mathrm{TiO} 2$ nanoparticles synthesized by microwave-assisted and solid-state diffusion route. Appl Nanosci $5: 419$

Nemade KR, Waghuley SA (2015b) Carbon dioxide gas sensing by $\mathrm{Ag} / \mathrm{TiO} 2$ composites prepared by solid-state diffusion and chemical routes. J Chinese Adv Mater Soc 3:9 
Ren X, Wu Y (2013) A low-overpotential potassium-oxygen battery based on potassium superoxide. J Am Chem Soc 135:2923

Zhang DH, Xue ZY, Wang QP (2002) The mechanisms of blue emission from $\mathrm{ZnO}$ films deposited on glass substrate by $\mathrm{rf}$ magnetron sputtering. J Phys D 35:2837

Zumsteg A, Ziegler M, Kanzig W, Bosch M (1974) Magnetische und kalorische Eigenschaften von Alkali-Hyperoxid-Kristallen. Phys Condens Matter 1974:267

\section{Publisher's Note}

Springer Nature remains neutral with regard to jurisdictional claims in published maps and institutional affiliations. 